Culture and Social Interaction

Elsevier Editorial system(tm) for Learning, Manuscript Draft

Manuscript Number: LCSI-D-15-00044R3

Title: Writing as a Mediational Tool for Learning in the Collaborative Composition of Texts.

Article Type: Regular Article

Keywords: dialogical self, recontextualization, learning, semiotic mediation, collaborative classroom writing, inner speech

Corresponding Author: Dr. Ian Thompson, PhD

Corresponding Author's Institution: University of Oxford

First Author: Ian Thompson, PhD

Order of Authors: Ian Thompson, PhD; Anne L Wittek, PhD

Abstract: This article explores the complex relationship between writing in the secondary school classroom as a tool for learning and the dialogical communicative processes involved in crafting and revising talk and inner speech into written speech. A theoretical framework is introduced from the work of Linell, Mercer, Vološinov and Vygotsky to develop a language of analysis for the dialogical processes involved in classroom composition. The framework draws on the concepts of the dialogical self, semiotic mediation and recontextualization. Empirically, the article reports on data from a qualitative case study of a state secondary English class for 13-14 year olds students in the UK that follows a sequence from classroom talk to a written text involving four students. The findings suggest that classroom writing that develops from socially mediated activity can become a dialogical tool for meaning making. The data reported on in this article challenge assumptions that dialogic classrooms are always spaces of concord and agreement. Critical incidents of discord, whereby students challenge, debate, argue, and ultimately recontextualise meaning, can be important precursors for some students to transform their resistance to dialogical learning. These findings suggest that more research attention should be paid to these complex processes of recontextualisation. 
*Detailed Response to Reviewers

Dear Roger

I have attended to the technical changes that you asked for.

Thank you for your help

Ian

an

an 
Writing as a Mediational Tool for Learning in the Collaborative Composition of Texts

Ian Thompson ${ }^{\mathrm{a}}$ and Anne Line Wittek ${ }^{\mathrm{b}}$

a University of Oxford, UK. Corresponding Author. ian.thompson@education.ox.ac.uk

${ }^{b}$ Univeristy of Oslo, Norway. a.I.wittek@iped.uio.no 


\title{
Writing as a Mediational Tool for Learning in the Collaborative Composition of Texts.
}

\begin{abstract}
This article explores the complex relationship between writing in the secondary school classroom as a tool for learning and the dialogical communicative processes involved in crafting and revising talk and inner speech into written speech. A theoretical framework is introduced from the work of Linell, Mercer, Vološinov and Vygotsky to develop a language of analysis for the dialogical processes involved in classroom composition. The framework draws on the concepts of the dialogical self, semiotic mediation and recontextualization. Empirically, the article reports on data from a qualitative case study of a state secondary English class for 13-14 year olds students in the UK that follows a sequence from classroom talk to a written text involving four students. The findings suggest that classroom writing that develops from socially mediated activity can become a dialogical tool for meaning making. The data reported on in this article challenge assumptions that dialogic classrooms are always spaces of concord and agreement. Critical incidents of discord, whereby students challenge, debate, argue, and ultimately recontextualise meaning, can be important precursors for some students to transform their resistance to dialogical learning. These findings suggest that more research attention should be paid to these complex processes of recontextualisation.
\end{abstract}

Keywords: dialogical self, recontextualization, learning, semiotic mediation, collaborative classroom writing, inner speech

\section{Introduction}

Research in the field of writing as a learning resource (e.g. Dysthe, 2002; Langer \& Applebee, 1987; Lerner, 2007) suggests that writing in its different forms has the potential to support learning. However, Ackerman (1993) points out that those who claim writing to be a unique tool for learning often "ignore the complexities of cultures, classrooms, assignments and other media that might equally facilitate learning (p.334)." Ackerman suggests that more attention needs to be paid to institutional cultures and the extent to which these cultures support particular forms of writing intervention. Our purpose in this article is to explore in depth some of the dynamic processes involved in written composition as a cultural 
Research on the processes involved in writing has shifted its focus in recent years from strictly cognitive accounts of learning to write and to revise content to fit genre conventions (e.g. Bereiter \& Scardemelia, 1987; Flower \& Hayes, 1981) to the importance of students acquiring knowledge of genre and the conventions of writing within a structured social setting (e.g. Bazerman, 2009; Myhill, 2009; Prior, 2009; Russell, 2010). Bazerman (2009) argues that the contexts of "genre, situation and social activity system" (p. 282) call in to play a variety of writing processes. Thus students encounter in situated contexts specific forms of writing through the mediational tools of particular textual norms and genre conventions. Research associated with the "writing to learn" movement in the USA (e.g. McCutcheon, 2008; Fecho, 2011) suggests that introducing an element of play or experiment into the activity of writing allows writers to develop and challenge their own ideas.

There is also much research evidence to suggest that dialogical pedagogy can be productive for students' learning (e.g. Alexander, 2008; Nystrand, 1997; Wells, 1999). The term "dialogic pedagogy" builds on Bakhtin's (1981) and Vološinov's (1973) concepts of the centrality of dialogue to the formation of mind and refers to the importance of dialogue in literate activities for effective teaching and learning. Other research (e.g. Karsten, 2014; Prior, 2010; Prior \& Shipka, 2003) has explored the relationship between writing and dialogic activity. There is also some research evidence that highlights the importance of the expressive mode of writing (Britton et al., 1975) as a mediational tool for development (e.g. Brandt, 1987; Smagorinsky, 1996). However, there is as yet little research on writing as a tool for students' learning within classrooms that frame writing as collaborative activities. 
In order to capture the negotiated nature of text production, we apply a dialogical approach to writing and define composition as a social communicative practice within situated contexts. The texts created are uniquely situated in communities with specific expectations and needs (Linell, 2009). Through the telling of situated social narratives, students engage themselves as well as their readers in cultural and dialogical meaning making that link both the reader's and the writer`s experience with the content of the text (Wittek, Askeland, \& Aamotsbakken, 2015). Accordingly, in this article a dialogical perspective is applied to the processes through which students negotiate meaning in the collaborative act of composing texts. We aim at a conceptual contribution, and suggest an analytical approach to the rich, complex collaborative activities of writing in school. In particular we will look at the role of writing as a tool in the development of an adolescent student's process of meaning making. We apply the concept of meaning making to capture the creation of meaning in a specific context, while learning refers to a higher level of cognitive development. Finally, we will discuss how activities of student writing could be designed in classrooms for the purpose of developing semiotic sense making.

\section{Theoretical Framework}

\subsection{Writing as a psychological tool}

Writing can be viewed as a psychological tool for cognitive development through which the disorder and fragmentation of inner speech is articulated into a new communicative form of written speech. Vygotsky (1986) argues that writing involves "the deliberate structuring of the web of meaning" as the writer draws on and internalizes a cultural sign system for communicative meaning making and then attempts to externalize in a written text to be read by others (p. 182). Olson and Oatley (2014) point out that the production of a written artifact uses the "reflexive properties of language for particular social purposes and in particular historical contexts" and is "open to design and analysis and to revision and reinterpretation" (p. 8). However, Brandt (1990) warns against an artificial separation between oral language learning and literacy (reading and writing) language learning as they both involve "figuring out how language and occasion work to bring meaning to each other (p. 6)." Just as we learn 
to speak through listening and interacting with others so writers are most likely to learn about writing from understanding the purposes and practices of other readers and writers. As Brandt (1990) puts it: "If the key knowledge for literacy development is finding how people do reading and writing, then literacy is indeed dependent on oral transmissions, for this knowledge must be passed mouth to mouth, person to person (p. 7)." Through the appropriation of a written sign system as a cultural and psychological tool, the writer builds on the situated cultural and contextual resources which are inherited from dialogue and social interaction and which are then transformed through the activity of producing a text. Wells (1999) argues that it is through "engaging with others in the social practices of interpreting and creating text" that an individual writer "is able to appropriate these cultural resources and use them for the construction of personal understanding" (p. 278).

For the purpose of conceptualizing in-depth from a dialogical perspective the role of collaborative production of texts in transforming cultural sign systems into a psychological tool for making meaning and cognitive development, we will elaborate on the following concepts of: the dialogical self; semiotic mediation; and recontextualization.

\subsection{The dialogical self}

The dialogical self refers to the complex interplay between the self and the social in the development of mind. According to Linell $(1999,2009)$ the dialogical self has two main components: contextual sense making and individual consciousness. The individual mind is social in that knowledge, norms, concepts and language originate in the social world. Contextual sense making can be defined as an "in situ" matter for both the speaker or writer and the interlocutors (Linell, 2009, p. 222). Linell (2009) defines consciousness as "knowing with others" (p. 79) which "implies being aware of one`s own thoughts, feelings and behaviors' as well as the perspectives of others" (p. 109). Consciousness then is interactional as "thinking involves a sort of dialogue with others" whether those others are actually present or not (Smagorinsky, 2007, p. 62). Internal and external voices are invoked and interpreted when the individual engages in reflective thinking. Vygotsky (1987) conceptualized the chaos and disorder of inner speech as the "evaporation of speech into thought" (p. 270). The concept of a dialogical self denies the existence of the purely independent subject. Rather, the self is both socially embedded and also a conscious agentic individual with a will and an 
ability to intervene in the world. However, the concept of agency for student writers in the classroom context involves complex social, cultural, historical and environmental factors including: students' histories and present realities as writers; teacher and student interaction; and social interaction between students. In this sense agency and consciousness are intertwined in the processes of writing and learning.

Linell (2009) asserts that "different discourses", or "social representations", and "voices" meet in the individual's mind largely through the use of language (p. 136). Vološinov (1973) identifies words as the very basis of thought, the "semiotic material of inner life-of consciousness (inner speech)" (p. 14). As Vygotsky (1986) argues, "if language is a practical consciousness-for-others and, consequently, consciousness-for-myself, then not only one particular thought but all consciousness is connected with the development of the word" (p. 256). In a discussion of the ideological nature of signs, Vološinov identifies the word as a unique form of sign in that it has the properties of semiotic purity, ideological neutrality, and the capacity to become an inner sign. However, since inner speech is an attempt to make sense through words and other signs it is also what Vološinov terms "a dialogue in the making" or part of the social process through which we make meaning (ibid, p. 90). These meanings are not fixed but are liable to change through social and verbal interaction and changing contexts. Vološinov defines dialogue in the broad sense of any form of verbal communication and argues that, "Any true understanding is dialogic in nature" (ibid, p. 102). Language then is made for an audience, the listener or reader, and is made up of ideological, social, unstable and creative aspects. If language is shared territory then meaning emerges from the social interaction between addresser and addressee that is in turn affected by the contexts of specific time, place and cultural factors. Karsten (2014), building on Vološinov's concept of refraction, whereby a word as a sign both represents a meaning and is evaluated form different perspectives, points out that in "dialogical processes, discord (i.e. variation) between utterances is just as important as approval (i.e., continuity) (p. 486)."

\subsection{Semiotic mediation}

An important assumption in our analytical framework is that human learning and thinking is mediated by culturally developed psychological tools or signs (e.g. Daniels, 2015a; Leontiev, 1974; Säljö, 1999; Vygotsky, 1987; Wertsch, 2007). As Wertsch (2007) puts it: "Instead of 
acting in a direct, unmediated way in the social and physical world, our contact with the world is indirect or mediated by signs" (p. 178), semiotic tools in particular. However, linguistic tools are not simply "codes with stable links between expressions and meanings" (Linell, 2009, p. 40) as words do not always have fixed and unique meanings. Rather, words can have partly open meaning potentials that users can interpret and infer. Word meanings change as they "are dynamic rather than static formations" (Vygotsky, 1986, p. 217). Sense making involves an interaction between the potentials of the linguistic resources and the act of communication with others.

Within classroom dialogues, semiotic mediation includes a variety of semiotic resources (Mercer, 2000) but also a range of voices or third parties (Linell, 2009). The process of writing involves interaction, not only with the culturally developed tools of language but also with a variety of dialogue partners (Wittek, 2013). Dialogue partners can be physically present, as in situations whereby two co-authors sit side by side and work on the same text or a when a teacher works on a text with a student. However, generalized others, based on ways of arguing or modes of thinking, can also take on the role of dialogue partners. Dialogue partners can also be speech genres and social languages defined by Linell (2009) as "dynamic, living activities, subject to alterations as situations, cultures and time changes" (p. 198). Within the realm of their studies, when faced with a given assignment, students have to negotiate how to deal with the institutional task that lies ahead of them. In these negotiations they will search for support from previous experiences and a range of third parties originating from contexts and social experiences both inside and outside of their educational context and across time. Even when students write ostensibly by themselves they interact with culturally developed tools representing certain voices and their historical paths.

Of course these voices are not always in accord in classroom talk. Mercer (2000) has categorized three types of classroom talk; disputational (self-orientated and competitive), cumulative (in agreement but uncritical), and exploratory (collaborative, critical and active). These categories suggest not only the developmental pedagogic function of exploratory classroom talk but also the importance of teachers creating the appropriate environment for talk to be developmental. Mercer describes "disputational talk" as the attempt by the participants "to keep their identities separate, and to protect their individuality" (Mercer, 2000, p. 173). Exploratory talk represents "a joint, co-ordinated form of co-reasoning in language, with speakers sharing knowledge, challenging ideas, evaluating evidence and considering options in a reasoned and equitable way" (Mercer \& Howe, 2012, p. 17). However, writing 
always involves interaction not only with culturally developed tools, such as genre conventions, but also with the "linguistic community in which both interlocutors are included (Linell, 2009, p. 94)."

\subsection{Recontextualization}

For the purpose of digging deeper into the complex cognitive processes that are involved in mediation, we will apply the Linell's concept of recontextualization (Linell, 1998, 2009). Linell (2009) defines recontextualisation as actions at a personal level where students "bring along some aspects of meaning from the "quoted" sources/contexts, but also they develop new meanings in the new "quoting context"" (p. 248). Recontextualisation draws heavily on experiences from participation in different contexts. The clusters of mediational cultural tools connected to collaborative production of written texts that students encounter in schooling can be conceptualized as material representations of core values and ideas, or ways of arguing or thinking, that are typically embraced in any subject disciplinary or professional culture.

Linell (2009) argues that when these mediational tools move between activities and situations, they are typically subject to processes of recontextualization. Students' dialogues, thoughts, and the texts that they create may cross the boundaries of different disciplines in school as students draw on their previous knowledge and understanding. Students have to recontextualize what is expected from them in each of these textual discourses. The collaborative production of texts involves a "difference-building process" (Linell, p. 73). Nystrand (1986) argues that the quality of writing comes from the relationship between writers and readers and their understanding of the conventions of a particular text genre. Learning to write effectively, from this perspective, is dependent on the degree to which students recontextualize the mediational tools that they use and explore with during the writing process. These tools mediate and reshape both the activity related to text production as well as the learning and thinking at both a social and a personal level (Vygotsky, 1987). Bazerman (2012) points out that "any fresh formulation, putting together words, phrases, and sequences of sentences not previously seen or heard by the writer, involves a deeper externalization, as the writer must convert meaning gists into publicly shareable thoughts by 
reformulating the linguistic repertoire the writer has at hand through prior social transactions (p. 268)."

\subsection{Summing up the conceptual argument}

There are multiple and sometimes conflicting voices engaged in processes of learning. From a dialogical perspective, learning is not located purely within the individual but rather in contextual social activity or in the interface between contextual sense making and individual consciousness. As Vološinov (1973) states, "To understand another person's utterance means to orient oneself with respect to it, to find the proper place for it in the corresponding context (p. 102)." Since inner speech is an attempt to make sense through the fragmentation of words and other signs it is also what Vološinov terms "a dialogue in the making" or part of the social process through which we make meaning (p. 90). These meanings are not fixed but are liable to change through social interaction and changing contexts. As writers attempt to articulate their fragmented inner thoughts through speech or writing they enter a social world whereby both speaker and listener, or writer and reader, share the interaction and shape meaning according to the contexts that affect them. Writing can be seen as a psychological tool through which the writer translates and transforms the chaos of inner speech. Writing, along with other forms of semiotic mediation, can thus play a role in the formation of the dialogical self which is formed from and through social interaction. It follows then that effective classroom research on the nature of learning to write has to focus both on the process of developing composition as well as the dialogues, both disputational and exploratory, that create the impetus for that writing.

\section{Methods}

This conceptual contribution aims at suggesting an analytical lens to address the ways in which collaborative activities of text production can mediate students' sense-making and learning from a dialogical perspective. For the purpose of illustrating our suggested model, we draw on a longitudinal qualitative case study (Yin, 2014) of an English class for 13 to 14 year olds in an inner city school in England reported in detail elsewhere (Thompson, 2012a; Thompson, 2012b; Thompson, 2013). The major findings of this study were that: 
collaborative writing can be an integral tool in the learner's own agency in creating a social environment for development; the situated context of writing is integral to the understanding of social mediation and the negotiation of meaning; it is the complex and recursive nature of writing that lends itself to the development of a learner's agency within this situated social environment.

This article focuses on a data set involving five students in the class, two of whom, Dwayne and Eva, went on to produce a short collaborative text. Following our theoretical position we addressed the following questions from the data:

- How did the students in this classroom move from disputational talk, to collaborative talk to collaborative writing? In what ways did the tensions involved in this semiotic activity lead to new learning?

- How did the collaborative writing activity Dwayne and Eva mediate their learning in the classroom and develop their dialogic selves?

- In what way did writing lead to a recontextualization of Dwayne as a writer?

The school in which the study was based was a state inner city high school of mixed social intake in a southern English city with examination results well below the national average. The school had 1200 students aged between 11-19. The writing sequence reported on here took place over the course of six lessons. A purposive sample of four students (identified here as Andy, Dwayne, Eva and Helen) who according to their classroom teacher had worked poorly together in previous lessons were video recorded and observed by one of the researchers. Cameras were focussed on both groups and on computer screens. Andy and Dwayne were both locally born boys of African-Caribbean heritage. Andy was described by his classroom teacher as being very articulate in discussions and working at an average level of expected attainment in writing. Dwayne was working well below national age level expectations for writing and was described as being difficult to manage in class. He rarely produced finished pieces of work. If challenged over lack of work Dwayne would quickly become aggressive and claim that he had been treated unfairly. Eva was a Polish immigrant who had been in the UK for four years. Her English level was very good overall and her writing above the national level. Helen and Yasmin were white local girls who were working at average levels of expected attainment in writing. 
The students had been given the task of collaboratively producing a school magazine for their parents. The data set includes videos of the sequence of English lessons, post session interviews with the teacher and students, and key students' written texts in an attempt to capture what Prior and Hengst (2010) describe as "the simultaneous, layered deployment of multiple semiotics (talk, gesture, artifact use and production, interaction with environmental structure) (p. 19)."

The key moments represented in the data analysis were critical incidents defined as moments that exemplify important developments in learning (Woods, 1993). The instances chosen for analysis are critical incidents where the collaborative element of learning established potential conditions of negotiation between student and teacher or between peers. These critical incidents involved one or more moments (defined here as episodes) that might involve dialogue around texts, instances of written composition, or gestural or positional evidence from video data. The identification and coding of these key moments of interaction between different actors as well as other voices and mediational resources was a key method of analysis or theoretical sampling of data based on the underlying theoretical position that learning is situated and involves mediation and negotiation of meaning. The theoretical basis of the codings used to identify critical incidents leading to the development of Dwayne's written text was initially based on Mercer's (2000) definitions of three types of classroom talk identified as:

1.Disputational (instances of individually motivated talk identified through argument and or aggressive gestures);

2.Cumulative (co-operative talk and activity indicated through discussion and/or conciliatory gestures );

3. Exploratory (collaborative talk and activity indicated through discussion and collaborative gestures).

Instances of classroom talk were then coded alongside types of instruction and activities related to collaborative classroom writing to produce the following categories:

\section{A. Disputational talk related to writing:}


B. Mediation through talk and collaboration related to writing:

1. Dialogical teacher/student interactions specific to the process of writing;

2. Dialogical student interactions specific to the process of writing.

C. Exploratory talk and activities related to writing:

1. Questioning: questions put by the teacher or students related to the process of writing that were instructional, directional or developmental;

2. Exploratory and collaborative student talk about composition;

3. Exploratory student interactions that appeared to be off task but led to periods of sustained writing.

The analysis of these codings established three critical incidents relating to the research questions that developed a change in the relationship over time between Dwayne and Eva and established the conditions for productive collaborative work:

Critical Incident 1: Students responding dialogically to teacher instruction;

Critical Incident 2: Cumulative interaction leading to disputation;

Critical Incident 3: Recontextualization through exploratory collaborative composition.

The dialogue from these episodes were transcribed from repeated viewings of the video. The dialogue is presented in relatively clean form here with latched or closely overlapped speech indicated by the symbol / and important gestures indicated in italics. The classroom episodes reported here follow a sequence as the adolescent writers moved from disputational talk, defined as talk characterized by the immediacy of spoken language where possible positions 
are uttered and made available to the involved people, to exploratory talk where the different positions were negotiated and acted upon, and finally to written composition. All students and teachers concerned in the research are referred to by pseudonyms.

\section{Findings: From Talk to Text in Collaborative Writing}

\subsection{Students responding dialogically to teacher instruction}

The first critical incident followed an attempt by the teacher to establish guidelines for collaborative procedure. Andy, Dwayne, Helen and Eva were involved in a group task of writing a magazine for their parents. Eva and Helen were from the editorial team and Dwayne and Andy had been asked to write articles. Both boys were reported by their teacher to be extremely reluctant writers but had been persuaded to write on a soccer match and school uniform respectively. The discussion (Episode One) focussed on the existing school newsletter for parents.

\section{Episode One}

Teacher: So what do you think of the newsletter?

Eva: It looks rubbish. No-one wants to read that.

Dwayne: Yeah. I just chuck it.

Teacher: So what's wrong the way it looks? What would you change? Andy, Dave, turn those screens off and listen. What's wrong with it?

Andy: It's all wrong. It's rubbish/

Dwayne: /It looks boring. Who wants to pick up that?

Eva: It doesn't catch your eye. It's patronising. It talks down to us like we don't know.

Teacher: So what could you do about it?

Eva: They could put in things like things that we want to read about. Ask parents what they want to know. 
Dwayne: Yeah we could ask people what they want to look at.

Teacher: How could you do that?

Eva: $\quad$ We could do a survey.

Teacher: Sounds a good idea. We'll come back to that. I suggest that before you start to allocate roles for the magazine that you get into groups and talk about what sort of magazine you want. What would your parents be interested in? What sort of articles should you think about writing? Next I suggest that you think about who is going to be the magazine's editorthe person who decides who writes what and how the magazine finally looks.

\begin{abstract}
Although the questions were generally open-ended there was a clear sense of guidance and instruction implicit in them. For example the response to Eva's suggestion of a "survey" was that though it was a "good idea" it would only be discussed later. Although the teacher used the term "I suggest" there was a strong sense of structuring discussion in a predetermined way with a clear reference to other voices like speech genres and social languages that the teacher refers to (such as magazines and the reading preferences of the teachers). In the video data some students were seen to turn around and log on to computers as the teacher spoke and did not appear to be listening at all. It was not clear from the video data what most of the pupils were doing but subsequent shots suggested that many had already started making notes whilst one had logged on and started to search for pictures of magazines.
\end{abstract}

After the initial discussion the students broke off into groups to discuss the project. Talk in the groups was animated and although the video data did not pick up detail of any group discussions pupils can be seen gathering in groups around computers and making notes. One group of girls was particularly lively and demanded the teacher's attention. From this group one girl, Eva, would soon appoint herself as the magazine editor with her three friends as subeditors.

Eva had appeared to be a relatively unconfident girl in previous lessons but in this session she was opinionated and passionate in her ideas. Initially Eva's group had wanted to be joint 
editors but the teacher decided to build on her enthusiasm and allowed her to take the lead with the rest of the group in charge of different pages of the magazine as sub-editors. In the whole class discussion that followed (Episode Two), the teacher began the discussion by saying that Eva wished to be the editor with her group as her helpers. Initially the other members of the class seemed happy to accept Eva although in subsequent discussion they were not clear about what the role entailed and disputes simmered between the editors and other class members. Various suggestions for pages were made: sports results, a fashion page, a gossip column, opinion pieces, and so on. Eva announced that the group were going to write a questionnaire to find out what their parents were interested in. The long list of questions they decided on can be grouped in the following three categories:

- What content would make you read a school magazine?

- Is it important to know students' names in the magazine?

- What visual aspects would make the magazine appealing?

There was a clear attempt in these questions to address the voices of their given audience but the questions also revealed certain assumptions (third parties) made by the students about visual appeal and subject content.

In practice, very few of the pupils went on to directly ask their parents these questions although most of them were able to articulate ideas based on their own experience of magazines and to relate this directly to the task at hand. For example, Eva had clear ideas about what she did not like in the existing school newsletter and an awareness of what she wanted in a new magazine based on her reading of commercial publications. The introduction of the task of creating a magazine alongside the concept of creating the questionnaire allowed students to get involved and build on their previous knowledge.

\subsection{Cumulative interaction leading to disputation}

In the next lesson coherent groups emerged who were responsible for creating different pages in the magazine (Episode Three). Each group was assigned a sub-editor by the editorial team 
with Eva in overall control of the process. Although the teacher deliberately resisted attempts to be directly involved in the editorial team, she often acted as a consultant to them. Nevertheless, she later explained that 'I was eager to let the pupils control the collaborative process as far as possible and was interested to see how they would negotiate problems.' All of the groups experienced significant tension between the writers and their sub-editor.

In the following sequence from lesson four (Episode Four), the teacher held a meeting with the editorial team (Eva, Helen and Yasmin) in which she addressed the issue of the role of editors and the conflicts in the groups. Her role here was subtle as by skilful use of questions she created a dialogue that allowed the students to develop their confidence in their role.

Episode Four

Teacher: Now why do you think there have been arguments?

Eva: $\quad$ Because some of em just won't listen to us. They don't take us seriously.

Yasmin: They think they know everything. They think we just boss them about.

Teacher: Do you think that's true? (The students nodded) So how can you get them to listen to you?

Helen: Make them. Shout at them.

Teacher: Do you think that will work? (The students all laughed at this) Have you asked them what they feel about their work?

Eva: $\quad$ Yeah but they're not listening to us. We tell 'em what they have to do but they keep on doing what they want. (The other students agree)

Teacher: Have you thought about having a meeting with the whole group where you explain to them that it is your role to ensure the magazine is actually put together? If you explain what you are doing and let them know that they are as important as you then they may respond better. What do you think?

Eva: $\quad$ It might work. 
Yasmin: Yeah if they think it's their own ideas they might do it.

Teacher: What do you think Helen?

Helen: We should just tell them.

Eva: No it's better to try to work together/

Yasmin: /No, Helen, we should have a meeting. (Downwards gesture with both hands)

The teacher here opened the dialogue by asking the team why there had been arguments, putting the onus on them to explain. In fact the teacher revealed later that she had become concerned about the domineering and dismissive attitude of the girls to some of the other students in the team. Eva and Yasmin were aware of the problem and Helen expressed their frustration by saying they should shout at them. The teacher continued to attempt to initiate dialogic interaction by asking open questions: "What do you think?" "Have you thought?" Even when the teacher directed the team by suggesting having a meeting, she followed up with a question. Yasmin's response was particularly interesting as her suggestion that the pupils would respond, "if they think it's their own ideas" was a subtle one that showed development in her thought process. The teacher then brought in Helen who clearly did not agree with the increasingly conciliatory Eva and Yasmin. Teasing out this disagreement allowed the exploration of different voices, possible positions, and possibilities for recontextualisation to remain open.

In a subsequent video sequence (Episode Five), filmed two lessons later, the editorial team sat around a table in animated debate. The students appeared in the video to be decisive and organised and took turns to speak. At times some of the students' body language appeared to be quite negative and Eva at one point gesticulated at one of her sub-editors who responded by shaking her head. The potential for conflict between writers and editors remained throughout the sequence. The following heated exchange was fairly typical:

Episode Five 
Dwayne: They're just criticizing our work. They don't do anything but criticize/

Helen: /shut up.

Andy: $\quad$ They're not listening to our points.

Helen: We are.

Andy: $\quad$ You are busting my work. (slams hand on desk)

Teacher: Isn't there some value in constructive criticism?

Eva: $\quad$ That's what we're trying to do.

Helen: We're trying to help you.

Andy: Then talk, don't just tell us.

Dwayne: Yeah talk.

Although the teacher's open question was aimed at both sides of the argument and was intended to prompt interaction it was Andy and Dwayne's request for "talk" that suggested they were ready to enter into dialogical discourse. From here onwards, there was progress in the discussion and Eva was able to make the point that the whole group needed to "work together." This process can be conceptualized as a form of sense making approved and enhanced gradually by the participants. Eva made such a stance explicit (Episode Six):

Episode Six

Eva: We have to work together. Everyone has their jobs and everyone has to listen to each other. Remember we are writing for other people to read and we have to make it good. We'll come and help people but we're doing it together.

At this point Eva stood up in front of the group and invited questions from the rest of the pupils by saying, "What do you think?" The students appear in the video data to be decisive and organized and can be seen taking turns to speak. At times some of the pupils' body language appears to be quite negative and both Eva and Dwayne can be seen gesticulating. However, at other times, they can also be seen nodding and looking at each other. This gestural evidence suggests now that the group had begun to develop their ability to 


\subsection{Recontextualization through Exploratory Collaborative Composition}

After the exchange described above, Eva went over to help Dwayne who had started to write a part of a sport article. The article incorporated a review of a soccer match in which Dwayne had apparently played a starring role. In the video evidence Dwayne initially read and corrected his own work whilst Eva stood behind him occasionally pointing over his shoulder at the screen. Dwayne sat at the front of his chair with his face close to the screen and his shoulders hunched as if he was trying to screen the computer monitor from Eva. Eva read the article and mumbled aloud some of the words, repeating them in a slightly revised order or with a different emphasis. For example, she changed the line, "It was a really tough and long match" to "The match was long and tough." Dwayne pointedly ignored any suggestions she made and said nothing to her at first. Dwayne then begins to read his own work aloud and Eva leans over to touch the keyboard and adds some punctuation and begins to change some of the sentence structure.

At this point Dwayne leaned over to allow Eva better access to the keyboard. The sentence, "I scored a great goal the best I had ever done", became "I scored a great goal! It must be the best I ever scored!" Dwayne then reads this and says he is not sure whether it "sounds right". Eva says it "looks better" but changes the second exclamation mark to a question mark. By "sound" Dwayne may have meant "read" but it appeared he also has a sense of an oral report in his mind whereas Eva concentrated on the visual appearance of the written words. 
Eventually Dwayne changed the line to, "It was my best goal ever." Both Eva and Dwayne expressed their happiness with the line and Dwayne felt it was less "big headed."

Although Eva was technically in a position of authority over Dwayne in this exchange as she was the editor and he the writer, their dialogue established a collaborative activity that resulted in a qualitative change in his writing as he moves from reportage to the expressive mode. Semiotic tools at play transformed during the exploratory dialogue. When Eva left Dwayne continued to write alone often sounding out inner words before writing, reading whole sentences aloud, cutting and changing words. The resulting text was both substantially longer than normal for Dwayne but, in both his and his teacher's opinion, qualitatively better. The last few lines are reproduced here.

The match felt long and tough. I was tired. On my last legs. Then the ball came over and I turned and hit it. Smack. A screamer. Top corner. Great goal. It was my best goal ever. I had won the game. WE had won the fight.

The continuous movement from disputational talk to exploratory talk within collaborative activity enabled Dwayne, with Eva's help, to produce an emotive and expressive written text. Put in theoretical terms, this can serve as an example of translation of the chaos of inner speech. In other words through the collaborative process of producing an article for the journal he recontextualized the semiotic tools at play. The potential for this is supported by the active interaction with peers and the semiotic tools applied in the writing activities. As he later recalled, 'I didn't know I knew what to write. I didn't know until I talked it out.' In a subsequent interview Dwayne was asked what the editors had said about his text.

Interviewer: Did any girls on the editorial team read your work?

Dwayne : Yeah Eva, Yasmin and Sarah I think.

Interviewer : What did they say?

Dwayne M: They said it was all right but I had to do some corrections and I had to work it out.

Interviewer: Do you know what you had to correct? 
Dwayne: Punctuation. Full stops. Capital letters. I had to write a bit more because I didn't write enough or something.

Dwayne remembered the advice he was given as a concentration on technical errors. In fact Eva made significant compositional suggestions that Dwayne implemented and this dialogue helped him to produce a sustained piece of writing. The fact that he did not mention this suggests that he had internalized the process of editing his work. Dwayne was then asked his opinion of how well the editors had worked with him.

Dwayne: They worked well because they told us what was wrong and we had to put it right. So that it could be perfect.

Interviewer: Could they have made you work hard if you didn't want to?

Dwayne: Um. Yeah I suppose so. I just don't do much. I talk.

Interviewer: When you finished your report were you pleased with it?

Dwayne: Yeah. It took me a bit of time but I thought I done well. I wrote about two pages of it.

The implication that Dwayne was proud of what he had written was significant as, according to his teacher, he had never previously expressed pleasure about writing in the classroom. His final comment suggested that he had learned far more form the project than he previously revealed in the interview. He talked about research, the production of his writing and the appearance of his text. Dwayne had recontextualized the essential steps in the process of writing an article.

\section{Discussion}

In the following section, we will elaborate on two themes that we find particularly interesting in the interface between our theoretical framework and the empirical example. These are: 1 . The transformation of sign meaning through the activity of the collaborative production of texts; 2 . The role of play and experiment in activities of writing. 


\subsection{The transformation of sign meaning through the collaborative production of texts}

Mercer (2000) describes language as a tool for intermental thinking through which we jointly engage in intellectual activity. The essentially dialogical nature of this situated activity of communication is based on "the interplay between situated interactions and sociocultural resources and practices" (Linell, 2009 p. 57). However, we are also concerned with the interaction between "a material sign form...and the object-oriented intentions and agency of speaker or listeners" (Wertsch, 2007, p. 185). The act of writing involves a dialectical tension between thought and object-orientated intention as the writer attempts to translate the interpersonal world of communicative activity first through inner speech and then by the use of the abstract form of symbolizing that is writing (Thompson, 2012a). As Vygotsky (1987) puts it, the "movement of thinking from thought to word is a developmental process (p. 250)." As talk is a tool for intermental social development, so writing as a cultural artefact can be viewed as a tool for intramental development as the writer draws on their socially acquired semiotic understanding. Or, more precisely, collaborative activities of text production in the right circumstances can become an important mediational tool for the development of the psychological functions of thought and reflection.

The empirical dataset illustrated the complex and multifaceted interactions involved in this particular a collaborative writing task, and how the actions related to writing and the emerging text that was gradually created formed mediational tools for development. Through the process of moving from a disputational to exploratory collaborative talk Dwayne was able to reflect upon meanings and encouraged to take a stance. Theoretically, we argue that these processes nurture a new level of language control, a level that allows critical awareness of one's inner speech. In processes of producing texts, students draw on and internalize sign systems inherited from social interaction and through activities as illustrated in the previous section. In light of this, writing as multilayered literate activity has the potential to enhance processes of transforming sign systems into inner speech and then into written text. Learning is always mediated and the mediation and recontextualisation of linguistic tools are particularly important in processes of contextual sense-making and individual consciousness. The potentials of the linguistic tools involved in written composition were negotiated upon by Eva, Dwayne and the other students. The words they used had partly open meaning potentials, 
and Dwayne recontextualised from the responses of his peers and his teacher, as well as from his previous experience of texts, as he interpreted and unpacked the most relevant use of the words for the particular purpose in this context (appealing to the readers of the magazine).

Writing is a way of orienting oneself. By formulating utterances in a written form, students need to find ways of expressing themselves in a way that can be understood as sense making in situ. In our empirical example, Dwayne needed to orient himself with respect to the sources that he drew on to apply certain signs and words in his text. At the same time, he had to find an appropriate place for these signs in the corresponding context, where parents were the audience and soccer the theme. However, it is through and in difference and misunderstanding in dialogues that the contradicting voices generate active positioning and thus cognitive development. A whole range of other voices were involved in the case we have presented. The teacher's voice and the instructions she gave was just one of the voices involved; the voice of the teacher was part of the structural arrangement, and its authoritative function was only partly questioned by the students. However, when the girls took on the role as editors, and thus the traditional role of the teacher, the other students started to question the authoritative position and also their own orientation towards the new structural arrangements of the voices in the classroom. There was disagreement on how to interpret the task, how to apply the tools at play, and how to solve the task that they had been given. The production of the text eventually became the site of collaboration between Dwayne and Eva. Dwayne ended up changing his text, despite his initial reluctance. However, these changes were not a result of just doing what he was told, but rather the result of interaction in the interface between mediated contextual sense making and individual consciousness. This interface opened up the possibilities for the transformation from culturally developed semiotic tools to psychological tools.

Theoretically we argue that these kind of activities nurture individual consciousness and thus contextual sense-making and learning. The processes of recontextualization involved means that the tools involved (systems of signs) move between activities and situations. Processes of recontextualization bring along some aspects of meaning from the original context, but they also bring about new meanings. These processes are of course being played out in shorter or longer timescales. 
The conscious reconstruction of semantic meaning through the mediation of psychological and physical tools within the activity of writing illustrated by the storyline presented in section 4 develops higher order cognitive processes and growth. In the empirical example, Eva physically left Dwayne but he continued the dialogue internally as he wrote through conscious thought rather than being hampered by his previous recollection of writing failure. These acts of communicative activity can be defined as 'dynamic, living activities, subject to alterations as situations, cultures and time changes' (Linell, 2009, p. 198). In this empirical case, the students continuously had to work with their developing conceptual understanding.

\subsection{The Role of Play and Experimentation in Activities of Writing}

In an earlier section, writing was conceptualized as actions of bringing together different signs, symbols and words into new senses of meaning within a particular social activity system. These processes are dialogical in nature: we are social beings, thoroughly dependent on each other as we develop our cultural and social understanding of the world around us. These processes involves both tension and conflict between sign system and intentions. In the UK school example a potential for conflict between writers and editors was present throughout the whole sequence. An interesting gestural movement was visible during the activity when, at an early stage in the process, Dwayne tried to keep Eva away from his work by hunching his shoulder as if he was trying to screen the computer monitor from Eva. However, they ended up rewriting Dwayne's draft in a manner that both of them found acceptable. Writing the article became a social activity both in inception and in composition and the translation of inner speech here involved active collaboration.

The communication between Eva and Dwayne gradually moved into exploratory talk; the students had to negotiate how to deal with the institutional task that lay ahead of them and the cultural expectations of active agents in that situation. They also negotiated ways to unpack the meaning potentials of the tools involved. Eva as an editor might search for support in how her teachers normally supervise the students, and she might have some ideas about the tasks of a journal editor. Dwayne, on the other hand, seemed to relate his role to the same conventions as he normally did as a student, and he clearly did not like not like Eva taking on the role of the teacher. However, in these negotiations they sought for support from previous experiences and a range of third parties originating from other contexts and social 
experiences. Invisible dialogue partners were present in all their utterances (verbal and gestural), but in the particular situation of the here and now they had to choose a way of using the resources available in ways that corresponded with the contextual "rules" and the task given by the teacher. The collaborative framing of the text production made the range of different voices visible and possible to act upon for the parties involved in the joint activity. The students were pushed to take a stance based on the complex interaction of many voices.

Dwayne's description of his goal took on an expressive quality as he reflected on his representation of his goal through words. Instead of scoring simply a goal, he scored 'a screamer'. Dwayne's path towards the storyline in section 4 illustrates how this particular experience of producing an article in collaboration with peers became a mediational means for experimentation through deliberate reflective activity and sense-making. The different tools involved in the intermental activity transformed into important interrelated psychological intramental resources. Collaborative processes of writing thus have the potential in the right circumstances to enhance contextual sense-making and individual consciousness. 


\section{Conclusions}

\subsection{Activities of writing - actions of sense-making}

Activities of writing are actions of sense-making as both writer and recipient are part of a "dynamic undertaking involving communicative activities and discursive movements" (Linell, 2009 , p. 223). Writing is not simply a matter of producing and perceiving mappings of reality. In producing written utterances, the writer affords material for making sense as well as for guiding the interlocutor's uptake and interpretation of the communicated meaning. Sense making is therefore a process. The transformative developmental relationships between social interaction in educational settings and the individual thought processes required for writing are both necessary and difficult. Writing is a complex activity that requires the conscious mastery of abstract thought through the mediation of psychological and physical tool usage. It is also contextual and dialogical, as the interaction in itself constitutes the path of contextual sense making and development of individual consciousness. The empirical case illustrates how processes of writing can enhance cognition and learning at upper secondary level. Writing develops high order critical concepts; it reflects the transformation and contextualization of mediational resources and thus enhances the development of the dialogical self. The data reported on in this article challenge assumptions that dialogic classrooms are always spaces of concord and agreement. Critical incidents of discord, whereby students challenge, debate, argue, and ultimately recontextualise meaning, can be important precursors for some students to transform their resistance to dialogical learning. These findings suggest that more research attention should be paid to these complex processes of recontextualisation.

\subsection{Implications for designing classroom writing activities}

Students' collaborative processes of writing within social activity systems have been highlighted in recent research (e.g. Blåsjø, 2004; Dysthe, 2002; Russell, 2010) that concludes that writing in its different forms has the potential to support processes of reflection and cognitive growth through the process of mediated activity. However, we argue that to develop the mediating potential of written activities within a group of students, activities of writing, and the social interaction that precedes it, must be organised in ways that give 
opportunities for the developmental sharing of thoughts and ideas. Writing sets a lot of semiotic tools into play, and the dialogical self is continually interdependent with other voices and contexts, moving between different positioning and continuities. Dialogic selves emerge as a "centre of subjective experience and agency, mutually dependent on other partners (directly and indirectly) in the interaction" (Linell, 2009, p. 113). The students in the English classroom were allowed to establish and develop dialogic interaction from an unpromising position of conflict. This, in turn, allowed our example Dwayne to develop as an expressive writer through the activity of writing an article about soccer.

Recent Vygotskian research on young and adolescent pupils experiencing difficulties with writing suggests that attention needs to be paid to the forms of social interaction played by active agents of change within mediated activity in the classroom (e.g. Bøttcher, 2011; Fisher, 2011; Thompson, 2012b; Thompson, 2013). Teachers of reluctant adolescent writers like Dwayne are therefore concerned with helping their pupils to develop the ability to write independently within the social contexts that both affect and influence social interaction within the classroom. By secondary school level many pupils have built up resistance to writing from their own past history of failure. The task for teachers of writing is to help create the social and environmental conditions for collaborative play and experimentation through writing that allow pupils to become both subjects and agents of their own transformation.

Written assignments that are given to students for the purpose of enhancing student learning need to be designed in ways that help students to unpack the potential meaning and functions of words in collaboration with others. Such activities of writing can open up possibilities for a new and higher plane of thought conceptualized in this article as individual consciousness within a social world. Writing activities should also be organised so that the writers become involved in integrative, connective and active exploring of the use of language within texts. This means paying close attention to both the design of instructional units (Smagorinsky 2015) and the design of classroom writing tasks (Thompson 2015). Classroom writing activities might include the following key design elements.

1. Opportunities for talk about the assignment before and during the process of writing.

2. The introduction of elements of "play" or experimentation into the activity of writing (illustrated here as exploratory talk), as these mediational tools help writers to develop and challenge their own thoughts. 
3. Students should be encouraged to interrelate experiences from different cultural contexts and with different dialogue partners though exploratory collaborative activity, as this enhances sense making and consciousness.

As Daniels underlines (2015), this is a view of pedagogy that is concerned with "a broadly based account of person formed in and forming culture and society (p. 7)."

Extended expressive writing tasks in schools can promote the crafting and revising of inner speech to create a communicative text and may encourage what Vygotsky (1986) identified as "deliberate analytical action" (p. 166). This action can involve the writer's active engagement with dialogue partners or generalized others. Writing, in this sense, can be seen as a dialogical tool for meaning making that develops from socially mediated activity. For secondary school students, classroom writing develops through interactions in a complex social and cultural setting. When students write, or help peers to write, they must control the intellectual process of translating inner speech and revising written text that in turn is derived from different social and cultural interaction. The dialectical process between these reflections and activities of writing and rewriting may enhance sense-making and consciousness in a powerful way. In this respect, writing can be viewed as a mediating tool through which students develop consciousness about the relationship between thought and language and make their own thinking visible and concrete. The strength of writing as a learning resource is connected to the function of reflective and deliberate control of the word, the word's meaning, and the word's function.

\section{Acknowledgements}

The authors are grateful to Harry Daniels and to the LCSI anonymous reviewers for their helpful commentaries on early drafts of this article.

\section{References}

Ackerman, J. (1993). The promise of writing to learn. Written Communication, 10(3), 334370. 
Alexander, R. (2008). Culture, dialogue and learning: Notes on an emerging pedagogy. In N. Mercer \& S. Hodgkinson (Eds.), Exploring talk in schools (pp. 91-114). London: Sage.

Bakhtin, M. (1981). The dialogic imagination: Four essays. Austin, Texas: University of Texas Press.

Bazerman, C. (2009). Genre and cognitive development: beyond writing to learn. In. C. Bazerman, A. Bonini \& D. Figueiredo (Eds.) Genre in a changing world (pp. 279-294). West Lafayette, Indiana: Parlor Press.

Bazerman, C. (2012). Writing with concepts: Communal, internalized, and externalized. Mind, Culture, and Activity, 19, 259-272.

Bazerman, C. \& Prior, P. A. (2004). Introduction. In C. Bazerman \& P. A. Prior (Eds.), What writing does and how it does it: An introduction to analyzing texts and textual practices (pp. 1-10). Mahwah, N.J.: Lawrence Erlbaum.

Bereiter, C. and Scardamalia, M. (1987). The psychology of written composition. Hillsdale, NJ: Lawrence Erlbaum.

Blåsjö, M. (2004). Studenters skrivande i två kunskapsbyggande miljöer. [Students’ Writing in Two Knowledge-constructing Settings]. Stockholm: Almqvist and Wiksell.

Bøttcher, L. (2011). Cognitive impairments and cultural-historical practices for learning: Children with cerebral palsy in school. In H. Daniels and M. Hedegaard (Eds.) Vygotsky and special needs education (pp. 11-29). London: Continuum.

Brand, A. G. (1987). The why of cognition: Emotion and the writing process. College Composition and Communication, 38(4), 436-443.

Brandt, D. (1990). Literacy as involvement: The acts of writers, readers, and texts. Carbondale, IL: Southern Illinois UP.

Britton, J., Burgess, T., Martin, N., McLeod, A. and Rosen, H. (1975). The Development of Writing Abilities (11-18). London: Macmillan.

Daniels, H. (2015a). Mediation: An expansion of the socio-cultural gaze. History of the Human Sciences, 28(2), 34-50.

Daniels, H. (2015b). Vygotsky and dialogic pedagogy. In press. (Unpublished manuscript).

Dysthe, O. (2002). Professors as mediators of academic text cultures: An interview study with advisors and master`s degree students in three disciplines in a Norwegian university. Written Communication, 19, 493-544.

Fecho, B. (2011). Writing in the dialogical classroom: Students and teachers responding to the texts in their lives. Urbana, IL: National Council of Teachers of English. 
Fisher, R. (2011). Failing to learn or learning to fail? The case of young writers. In H. Daniels and M. Hedegaard (Eds.) Vygotsky and special needs education (pp. 48-64). London: Continuum.

Flower, L., \& Hayes, J. R. (1981). A Cognitive process theory of writing. College Composition and Communication, 32(4), 365-387.

Graue, B. (2006). Writing in education research. In C. F. Conrad \& R. C. Serlin (Eds.), The SAGE handbook for research in education: engaging ideas and enriching inquiry (pp. 515528). Thousand Oaks, CA: SAGE.

Karsten, A. (2014). Writing: Movements of the self. Theory \& Psychology, 24(4), 479-503. Langer, J. A. \& Applebee (1987). How writing shapes thinking: A study of teaching and learning. Urbana, IL: NCTL.

Leontiev, A. (1974). The problem of activity in psychology. Soviet Psychology. 27(1), 22-39. Lerner, N. (2007). Laboratory lessons for writing and science. Written Communication, 24(3), 191-222.

Linell, P. (1998). Approaching dialogue: Talk, intercation and contexts in dialogical perspectives. Amsterdam: John Benjamin.

Linell, P. (2009). Rethinking language, mind, and world dialogically: interactional and contextual theories of human sense-making. Charlotte, N.C.: Information Age Publications.

McCutcheon, D. (2008). Writing and cognition: Implications of the cognitive architecture for learning to write and writing to learn. In C. Bazerman (Ed.) Handbook of Research on Writing (pp. 279-294). Mahwah, New Jersey: Erlbaum.

Mercer, N. (2000). Words and minds: How we use language to think together. London: Routledge.

Mercer, N. (2008). Talk and the development of reasoning and understanding. Human Development, 51(1), 90-100.

Mercer, N. \& Howe, C. (2012). Explaining the dialogic processes of teaching and learning: The value and potential of sociocultural theory. Learning, Culture and Social interaction, 1, $12-21$.

Myhill, D (2009). From talking to writing: Linguistic development in writing. British Journal of Educational Psychology, 11(6),27-44.

Nystrand, M. (1986). The structure of written communication: Studies in reciprocity between writers and readers. London: Academic Press.

Nystrand, M. (1997). Opening dialogue: Understanding the dynamics of language and learning in the English classroom. New York: Teachers College Press. 
Olson, D. \& Oatley, K. (2014). The quotation theory of writing. Written Communication, 31(1), 4-26.

Prior, P. (2009). From speech genres to mediated multimodal genre systems: Bakhtin, Volosinov, and the question of writing. In C. Bazerman, A. Bonini, and D. Figueiredo (Eds.) Genre in a Changing World (pp. 17-34). Fort Collins, CO: WAC Clearinghouse and Parlour Press.

Prior, P. \& Hengst, J. (2010). Introduction: Exploring semiotic remediation. In P. Prior \& J. Hengst (Eds.) Exploring semiotic remediation as discourse practice (pp. 1-23). Houndsmill, UK: Palgrave Macmillan.

Prior, P., \& Shipka, J. (2003). Chronotopic lamination: Tracing the contours of literate activity. In C. Bazerman \& D. R. Russell (Eds.) Writing selves/writing societies: Research from activity perspectives (pp. 180-238). Fort Collins, CO: The WAC Clearinghouse.

Russell, D. R. (2010). Writing in multiple contexts: Vygotskian CHAT meets the phenomenology of genre. In C. Bazerman (Ed.) Traditions of Writing Research (pp. 353-364). New York: Routledge.

Säljö, R. (1999). Learning as the use of tools. In K. Littleton \& P. Light (Eds.), Learning with computers: Analyzing productive interactions (pp. 144-161). London: Routledge.

Smagorinsky, P. (1997). Personal growth in social context: A high school senior's search for meaning in and through writing. Written Communication, 14, 63-105.

Smagorinsky, P. (2007). Vygotsky and the social dynamic of classrooms. English Journal, 97(2), 61-66.

Smagorinsky, P. (2015). Designing the task of teaching novice teachers to design instructional tasks. In I. Thompson (ed.) Designing tasks in secondary education: Enhancing subject understanding and student engagement (pp.191-206). London and New York: Routledge.

Thompson, I. (2012a). Stimulating reluctant writers: A Vygotskian approach to teaching writing in secondary schools. English in Education, 46(1), 84-91.

Thompson, I. (2012b). Planes of communicative activity in collaborative writing. Changing English. Changing English, 19(2), 209-220.

Thompson, I. (2013). The mediation of learning in the zone of proximal development through a co-constructed writing activity.' Research in the Teaching of English, 47(3), 247-276.

Thompson, I. (2015). Communication, culture, and conceptual learning: Task design in the English classroom. In I. Thompson (Ed.) Designing tasks in secondary education: Enhancing 
subject understanding and student engagement (pp.86-106). London and New York: Routledge.

Vološinov, V. N. (1973). Marxism and the philosophy of language. Cambridge MA: Harvard University Press.

Vygotsky, L. S. (1986). Thought and language. Cambridge, MA: MIT Press.

Vygotsky, L. S. (1987). Thinking and speech. In L. S. Vygotsky, Collected Works (Vol. 1, pp. 39-285). New York: Plenum.

Wells, G. (1999). Dialogic inquiry: Towards a sociocultural practice and theory of education. New York: Cambridge University Press.

Wertsch, J. V. (2007). Mediation. In H. Daniels, M. Cole \& J. Wertsch (Eds.), The Cambridge Companion to Vygotsky (pp.178-192). Cambridge: Cambridge University Press.

Woods, P. (1993). The nature and significance of critical educational events. London: Falmer Press.

Wittek, A. L., Askeland, N. \& Aamotsbakken, B. (2015). Learning from and about writing: A case study of the learning trajectories of student teachers. Learning, Culture and Social Interaction. doi:10.1016/j.lcsi.2015.02.001

Wittek, L. (2012): The activity of "writing for learning" in a nursing program. Outlines. Critical Practice Studies. 14(1), 73-94.

Woods, P. (1993). The nature and significance of critical educational events. London: Falmer Press.

Yin, R. K. (2014). Case study research: Design and methods (5th edition). London: SAGE. 